
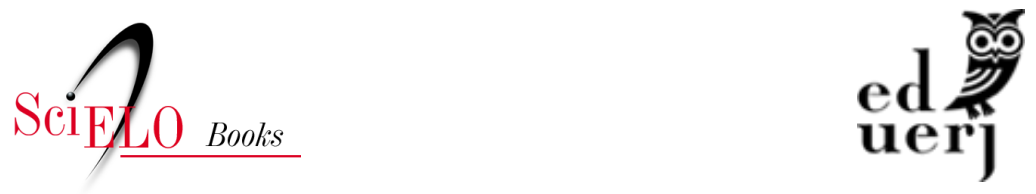

\title{
Diálogos entre natural, vegan e vivo
}

\author{
Maria Cláudia da Veiga Soares Carvalho
}

\section{SciELO Books / SciELO Livros / SciELO Libros}

CARVALHO, M. C. V. S. Diálogos entre natural, vegan e vivo. In:

Bricolagem alimentar nos estilos naturais [online]. Rio de Janeiro:

EDUERJ, 2013, pp. 89-103. ISBN: 978-65-88808-07-8.

https://doi.org/10.7476/9786588808078.0007.

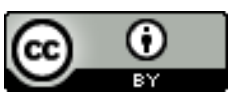

All the contents of this work, except where otherwise noted, is licensed under a Creative Commons Attribution 4.0 International license.

Todo o conteúdo deste trabalho, exceto quando houver ressalva, é publicado sob a licença Creative Commons Atribição 4.0.

Todo el contenido de esta obra, excepto donde se indique lo contrario, está bajo licencia de la licencia Creative Commons Reconocimento 4.0. 


\section{Diálogos entre natural, vegan e vivo}

\section{O refinamento do vegan}

Nas práticas de alimentação, o estilo vegan - uma reedição do vegetarianismo - se distancia do natural por seu investimento num refinamento do comer e se aproxima dele por sua semelhan-

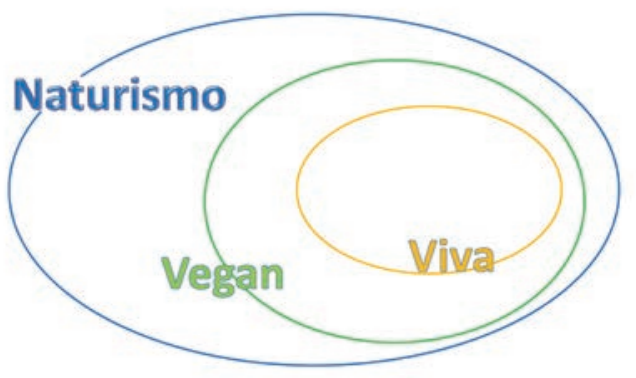
te contraposição ao estilo fast food. Porém, em linhas gerais, o estilo natural engloba os outros dois em seu universo de significação, pois reúne uma variedade maior de possibilidades em função de sua flexibilidade nas regras desse jogo.

O refinamento do estilo vegan se reproduz num habitus elitista e intelectualizado, que lhe confere distinção social. "Deve-se levar em conta que a procura consciente ou inconsciente da distinção toma inevitavelmente a forma de uma busca do refinamen- 
to e pressupõe o domínio das regras desses jogos refinados que são o monopólio dos homens cultivados de uma sociedade" (Bourdieu, 1992, p. 21). O estilo vegan busca esse refinamento e usa a filosofia e os personagens históricos em sua militância acirrada para afirmar essa distinção social, reivindicando uma herança vegetariana para a espécie humana no início dos tempos. Montanari fala que não por acaso a tradição grega e latina é rica em filosofias vegetarianas; o vegetarianismo era uma filosofia que se opunha a um modelo cultural construído como "bárbaro". Segundo ele, a tensão entre vegetarianos e carnívoros foi de tal modo influente que nem dois milênios seriam suficientes para apagar a disputa entre o mundo dos refinados e o dos "bárbaros": "De um lado, os povos do sul, sóbrios e frugais, afeiçoados aos produtos da terra e aos alimentos vegetais. De outro, os povos do norte, vorazes e carnívoros" (2003, p. 141).

Contreras e Gracia (2005) falam sobre as proibições de alimentos de origem animal em relação aos de origem vegetal, sugerindo que a carne tem sido foco de tabus na história. Historicamente, ela representou um objeto de controle nas relações sociais e culturais em diversas culturas. Para os vegetarianos, uma comida sem carne garante melhores condições de vida porque evita tanto reações agressivas das pessoas em suas relações sociais quanto uma sensação de mal-estar no corpo durante o processo digestivo. No mundo dos carnívoros, a carne tem sido considerada o alimento principal das refeições, funcionando como um indicador social de melhores condições de vida em vários momentos da história, a ponto de se medir a prosperidade de grupos sociais pelo consumo per capita de carne.

O fato é que a comida com ou sem carne representa uma riqueza e um prestígio para o homem em suas relaçôes sociais ao longo da história. Desde o momento em que o homem se diferenciou dos outros animais, preparando e socializando sua refeição, fez-se outro em sua organização social de forma estrutural, 
nas divisões de trabalho. Engels (1964), ${ }^{1}$ em sua pesquisa sobre a origem da família na construção da organização social, discute o processo de constituição de estruturas básicas na sociedade, em que a primeira divisão do trabalho é a que se fez entre o homem e a mulher para a procriação do filho. $\mathrm{O}$ desenvolvimento de técnicas para cultivo do solo, a partilha da produção e a divisão do trabalho estão na base da formação dos núcleos familiares, que, segundo ele, desde o começo, está relacionada aos serviços da agricultura. As práticas de alimentação estão no alicerce das estruturas sociais e vão desde como conseguir o alimento - o plantio ou o extrativismo, a caça ou a criação - até quem vai se ocupar das tarefas domésticas - o plantio e o preparo de alimentos - e sair para procurar comida. A organização de papéis masculinos e femininos que reproduzimos até hoje está relacionada à alimentação e a essa divisão em termos de formação de núcleos familiares.

Nos modos tribais coletivos de alimentação, já se havia determinado gêneros alimentícios comestíveis e uma escala de valores entre alimentos bons e ruins, sagrados e proibidos. $\mathrm{O}$ processo de organização social em algumas tribos antigas seguia uma ordenação na distribuiçãao da comida em relação a que momento haveríamos de comê-la e em que situação, comida de festa ou do cotidiano, quais alimentos seriam comidos crus e quais seriam cozidos.

Conhecer os significados que a carne assume é uma forma de se apropriar das experiências vividas e rememoradas coletivamente, embora nem sempre isso aconteça de modo consciente. O gosto é um jeito de se apropriar de uma cultura reunindo, na percepção de um alimento, um caráter coletivo que não se opõe ao individual, mas que o complementa. Produzindo

1 Não desenvolvemos crítica aos aspectos funcionalistas presentes nessa obra, quando o autor cita Morgan, por não considerar essa questão pertinente neste momento. 
ou reproduzindo relaçôes entre o corpo e o alimento, "o gosto e o paladar, em vez de se naturalizarem, são, portanto, cultivados no emaranhado da história, da economia, da política e da própria cultura” (Canesqui e Garcia, 2005b, p. 11). Gostar de determinados alimentos distingue os grupos sociais; nesse caso, não comer carne animal identifica o estilo vegetariano com um refinamento social que atualiza consensualmente o prestígio do vegetarianismo ao longo da história nas práticas de alimentação.

O discurso vegetariano se apropria dessa história reivindicando um status de prática alimentar pré-histórica com antigos defensores, como Hipócrates, ou populações ícones de uma vida saudável vegetariana, como os honza e os gregos, conforme Ossipow (1989). O habitus vegano desenvolve uma disposição para um projeto de mundo sem matança animal, rememorando grandes nomes de prestígio na história da humanidade. Em certa ocasião, um comensal provocou o proprietário vegetariano de um restaurante: o que achava de Hitler ser vegetariano? E ele respondeu que este só era vegetariano por influência de um general seu estrategista, pois o próprio Hitler, como idealizador do nazismo, não podia ser associado ao estilo.

A militância vegan articula fé e ciência. Praticamente todos os veganos com os quais convivi desenvolviam alguma espiritualidade com tendência ao sincretismo Ocidente e Oriente, além de um espírito de bricolagem. Considero exemplar uma imagem que registrei numa visita a uma casa vegan: na sala, havia um altar baixo, numa mesinha de cabeceira, com uma infinidade de imagens - indianas, budistas e católicas -, todas misturadas sem grandes formalidades, de metal ou papel, em pé ou deitadas. Era como se cada imagem pudesse complementar uma entidade maior, uma nova entidade que era capaz de proteger a casa.

Os entrevistados veganos desenvolviam suas crenças não necessariamente de acordo com uma religião, como católica, hebraica ou muçulmana, mas com uma mistura de imagens: Jesus 
Cristo, santos católicos e entidades da umbanda, gurus ou mestres orientais. Uma entrevistada relatou várias situações em que sua vida fora iluminada em função de sua devoção a mestres orientais como Inaiatcan e Krisnha, São Benedito, protetor dos cozinheiros, e Santa Bárbara, dos raios e trovões. Como se cada um se adequasse a determinada passagem de sua vida. Outra me contou que praticou o budismo e que seu espírito ficava mais leve e livre na meditação budista. Ela se diz adepta do cristianismo, embora não frequente a Igreja Católica, e cita a Bíblia para fundamentar sua liberdade religiosa: "Onde tem mais de um reunido...". Foi criada com pai protestante e mãe católica, numa relação tensa entre os dois, e se colocava fora dessa briga, livre para as misturas.

O sentimento de militância é uma marca no campo vegan. Quando eu respondia que não era vegana, era como se isso ativasse esse sentimento; alguns antecipavam que eu me tornaria vegetariana no decorrer da pesquisa, e outros lançavam mão de argumentos variados para me convencer a ser vegan. No entanto, ainda que a militância estivesse sempre pronta para a ação, os princípios de honestidade e honra sustentavam uma concepção de igualdade que ficava clara no respeito às diferenças, pois "ninguém sabe mais do que ninguém". Esse respeito impedia em parte uma violência simbólica; digo em parte porque filmes e fotos disseminados pelos ativistas veganos apresentam as mais sangrentas e perversas torturas com animais jamais vistas em filmes de ficção ou documentário do mundo animal.

$\mathrm{O}$ vegetariano é colaborativo com a pesquisa científica e a universidade. Não houve resistência alguma à pesquisa e à minha permanência nos restaurantes veganos; ao contrário, traziam-me documentos informais, como folhetos, reportagens e filmes, que defendiam os direitos dos animais e as vantagens de uma alimentação vegana, ainda que o objetivo da pesquisa nunca tenha sido o de confirmar uma hipótese sobre um jeito correto de se alimentar. $\mathrm{O}$ vegano tem disposição para o debate crítico, em geral 
numa apropriação envolvendo o conhecimento científico, numa perspectiva de senso comum, mítica. Numa entrevista, o Manual Waerland da saúde foi citado como explicação "genial e fantástica" sobre a digestão do animal. A narrativa continha elementos míticos: "Contam que esse filósofo, Waerland, que sabe muita bioquímica, esteve mal de saúde e desenganado pelos médicos antes de estudar medicina e encontrar no vegetarianismo uma solução para ele".

A concepção de "química" pode também expressar essa significação mítica na encarnação de uma entidade. "Química” é uma entidade do mal representada em alguma substância prejudicial à saúde, que simboliza a perversidade presente no processo de industrialização e urbanização modernas. $\mathrm{O}$ mal que se estabelece na concepção de "química" tem eficácia simbólica, situada na magia de seu feiticeiro, como diria Lévi-Strauss. O significado não pode ser percebido nem interpretado pelos instrumentos científicos de medida constituídos por uma "ciência" da nutrição. A ideia de "química", assim como a de energia vital, não é mensurável nem verificável numa bancada de laboratório bioquímico; ela é simbólica.

A busca por um argumento científico favorável ao vegetarianismo, numa tentativa de valorização e reconhecimento social, muitas vezes lhe é desfavorável, pois demonstra um caráter não científico no campo da ciência da nutrição, levando-se a uma desvalorização desses argumentos. No entanto, os instrumentos de interpretação da ciência devem ser sensíveis à cultura, calibrados pelas regras de um jogo simbólico que confere sentido a esses nomes nas práticas de alimentação em determinado contexto social, numa dimensão específica, e não do universo global. Uma concepção de energia vital estaria vazia de significados e sentidos se analisada num laboratório de bromatologia, da mesma forma que o princípio ativo de uma medicação homeopática não pode ser identificado num procedimento alopático. A interpretação demanda um olhar capaz de inserir uma concepção de energia vital dos alimentos em seu habitat, a alimentação viva. 


\section{A energia vital e o alimento vivo}

A busca pela energia de uma alimentação crudívora não é recente. Segundo Ossipow, os crudívoros do passado também eram germinadores de grãos como os de hoje, e a principal imagem da germinação é a da energia da vida: "Para eles, os alimentos não podiam ser medidos por unidades de caloria, mas em termos de vitalidade" (1994, p. 49). Levenstein (1994), em 1940, após a Segunda Guerra Mundial, estudou a dieta dos honza do Himalaia, que, além de vegetarianos, faziam uso de alimentos germinados. Essa cultura, tanto na perspectiva do crudivorismo quanto do vegan, era considerada um exemplo de saúde a ser seguido.

A alimentação viva se articula com a vegan. Os alimentos, além de crus, são somente de origem vegetal, com preferência para frutas e sementes; a ideia de energia vital é a principal motivação nesse tipo de dieta. A energia do alimento vivo não segue as leis da física, não é osmótica, cinética, elétrica, eletromagnética, mecânica, química ou luminosa, mas uma energia que dá vitalidade aos sujeitos por meio do simbolismo que envolve narrativas míticas sobre prolongar a vida e viver sem doenças. Tentamos compreender os sentidos do vivo observando o universo no qual se elabora e se realiza a magia da energia vital - como diria Bourdieu, passando do feiticeiro para seu universo social (1989b, p. 287).

Alguns itens da alimentação viva, como os brotos, são também muito utilizados nas refeições pelos naturistas e veganos, consumidos como verduras, em saladas. No entanto, para o vivo, os alimentos em crescimento ou germinação não são só complementares, consumidos em salada, são preferidos a todos os outros, utilizados como principais na refeição. Na culinária viva, a diversidade de espécies vegetais é muito mais importante do que o tipo de preparação: o alimento tem sua vida na natureza e a escolha é pelo que ele é, e não pelo que fazemos com ele nas preparações culinárias. Se na cozinha vegana ou naturista há um bife de glúten 
como prato principal e cereais cozidos como guarnição, na viva os alimentos se distribuem no prato em igualdade de condiçôes; não existe uma preparação principal que é guarnecida por outras. Todos os alimentos são crus ou ligeiramente aquecidos, denominados amornados, e o arranjo na refeição depende das texturas, cores e suculência dos alimentos. Isso de forma alguma implica monotonia, pois os alimentos nos pratos formam, com a variação de texturas e cores, desenhos como obras de arte. Segundo uma das professoras, na alimentação viva come-se arte. Vários alimentos são elaborados dentro das regras do vivo, conforme uma culinária natural, como empadinhas, bolos, cremes, queijos e leites vegetais, onde não há cozimento algum. A técnica culinária aproveita a consistência firme dos grãos germinados para fazer alimentos mais sólidos e moldáveis, nos bolos e nas empadinhas, e usa o sumo de frutos oleaginosos batidos em liquidificador para fazer leites, cremes e queijos.

É uma prática que aprofunda o aspecto caseiro do estilo natural numa vertente artística. No vivo, a estética é a da aldeia indígena da floresta, que atualiza o comer ancestral, da espécie, de uma sociedade tribal, no sentido de proximidade com a $\mathrm{Na-}$ tureza. Simula nas práticas de alimentação um ambiente natural, sem fogão, longe da cozinha convencional. Quase toda a culinária viva tem de ser desenvolvida pelos próprios comensais e demanda uma habilidade que deve ser apreendida em orientações, treinamentos e cursos. Germinar grãos ou sementes no ar é uma técnica que consiste em condicioná-los em vidros com um pouquinho de água, a tampa coberta por tela para proteção, de 24 a 48 horas em média, quando chegam à sua vitalidade máxima, ideal para o consumo, num estágio anterior à brotação. Nesse estado, os grãos mudam sua consistência, ficando mais macios, e possibilitam uma manipulação culinária específica para elaboração de massas de empadinhas ou de tortas e pastéis, e até de pães, oriundos de sua maceração. 
Essa técnica da germinação visa proteger e promover a vida em conjunção com seu ambiente natural. $\mathrm{O}$ cozimento "mata as enzimas", o que representa um alimento sem vida, e o objetivo do vivo é substituir "a morte pela vida". O máximo a que se submete um alimento em termos de calor é aquele que nosso corpo aguenta. Os alimentos denominados amornados são os colocados em água quente até a temperatura que nossa mão suporta. Assim, uma boa parte dos alimentos dos grupos dos cereais e das leguminosas, como arroz e feijão, não entra nesse estilo, porque só poderia ser consumida cozida. Segundo uma adepta, "um alimento pronto para consumo, após sete horas, já está perdendo sua energia vital. Essa potência que a energia vital [é capaz de reconstituir] é que a gente perde".

$\mathrm{O}$ vegetal em germinação carrega o sentido de uma força cósmica e, quando consumido cru, pode transferir certo potencial dessa força para outra vida, a de quem o come. Novos paradigmas de pensamento orientam essa alimentação, embora nem sempre de modo consciente. $\mathrm{O}$ que está em jogo nessa alimentação é como a percepção da energia vital, que pode ser objetivável na realidade por meio dos germinados, tem eficácia simbólica para os adeptos desse estilo. Segundo uma entrevistada, com o vivo ela se sente com energia de criança e adquire muita resistência: "Trabalho de oito a uma da madrugada pulando corda, porque como o alimento vivo. A energia muda a gente. Quando iniciamos comendo melhor, vai pingando uma coisa aqui, outra ali [dá vontade de fazer ioga], e depois a gente muda tudo".

A alimentação viva, mais do que os outros dois estilos, desenvolveu uma crença na cura, na capacidade do ser humano de reagir ao adoecimento, o que implica, assim como ocorre no estilo natural, uma resistência ao que o mundo faz com o homem, pois "o vivo é aquilo que o mundo moderno não faz". Nesse jogo simbólico, o alimento moderno é aquele que adoece o homem, e o aumento de doenças como o câncer é exemplo disso; portanto, 
é preciso sair desse mundo para outro, que se constrói simbolicamente na floresta e na aldeia.

Quando visitei o núcleo Terrapia, observei uma disposição e um respeito em relação à cultura indígena. Alguns usavam artefatos de madeira nas orelhas, sustentando aberturas grandes no lóbulo, do mesmo modo que certos grupos indígenas. Não que essa prática seja própria do vivo. A juventude atual usa piercings variados; porém, quando esses artefatos estão associados a outros aspectos da alimentação viva, assumem um caráter diferenciado. Numa ocasião festiva, fizeram uma apresentação em que alguns pintaram o corpo e cantaram um tipo de música diferente, com o ritmo semelhante aos cantos indígenas, evocados em rodas, com frases musicais curtas e muito repetidas, numa espécie de homenagem à Natureza. Outro núcleo de alimentação viva, na PUC-Rio, também faz encontros em que reproduz cantos de agradecimento dos povos guaranis, como um ritual prévio ao comer.

$\mathrm{O}$ ambiente mágico que se constrói no retorno a uma $\mathrm{Na}$ tureza sagrada se assemelha ao mito de Gaia, discutido no próximo capítulo. Por ora, gostaríamos de ressaltar uma disposição para o agradecimento presente nesses cantos - ninguém tocava no alimento antes de acabar a música. Num encontro, participei de uma cantoria que fazia agradecimentos a Deus e a elementos da Natureza, como terra, água e fogo, as forças que nos protegem. Em outro, as pessoas, em roda também, cantavam as músicas livremente, mas de modo muito sentimental e expressivo.

A alimentação viva, assim como a vegan, mistura-se com a ciência. Dois núcleos importantes estão situados em universidades, na Pontifícia Universidade Católica do Rio de Janeiro (PUC-Rio) e na Escola Nacional de Saúde Pública (ENSP). O Terrapia é um projeto social da ENSP, que, desde 1997, tem como objetivo difundir os princípios e hábitos de vida ecológica como caminho para a promoção da saúde. Oferece atividades variadas de cuidados com o corpo e a germinação de alimentos, 
cursos de culinária viva - em que apresenta técnicas sem uso de fogão ou geladeira - e alimentos pouco conhecidos, como folhas nativas oriundas de sua horta orgânica.

Num seminário sobre alimentação e cultura (que aconteceu no auditório da ENSP), um representante do Terrapia subiu ao palco e, com a simplicidade típica e sem constrangimento por se tratar de um evento científico, convidou a plateia a levar uma vida mais viva e humana na alimentação viva. $\mathrm{O}$ mundo da alimentação viva produz encantos, um retorno a uma Natureza ancestral, embora não em termos de ruralidade, mas de uma vida extrativista mais feliz, porque fora do ritmo acelerado do fast food. O habitus na alimentação viva não está voltado a uma filosofia de vida como o vegan, mas à terapêutica.

O paradigma vitalista, ou da vitalidade, que se contrapóe ao clássico/moderno orienta tanto o estilo de alimentação viva quanto o vegan e o naturismo. No vivo, guia um projeto propenso a reproduzir a alimentação com sentido de terapia mais como arte do que como ciência (Luz, 2000). O vivo se expressa com beleza na aparência dos pratos com flores, desenhos e cremes de frutas sempre muito coloridos, reforçando uma estética mais ainda do que os outros estilos. O paradigma da vitalidade valoriza o vigor, a força e a beleza (Luz, 2003). Opera com as concepções de integralidade e vitalidade. Enfatiza os resultados das práticas muito mais que o método e, por isso, orienta atividades com estratégias mais humanizadas. Envolve profissionais não obrigatoriamente graduados na área de saúde das universidades, mas mestres ou praticantes com experiência na vida. Uma de suas mais importantes seguidoras, Ana Branco, é artista plástica. Os praticantes, não necessariamente doentes, encaram a energia vital como saúde.

A concepção de vitalidade está fundamentada no comedimento, com representações positivas de equilíbrio e harmonia do corpo. Os modos das pessoas à mesa são controlados, sem excessos. A comida é harmoniosa e equilibrada tanto nas cores, texturas 
e formas dos alimentos quanto nas quantidades colocadas. O que se deseja é comer somente o suficiente. Um corpo traz em si, internamente, a quantidade de alimento que necessita. Ouvi alguns dizerem que essa quantidade era natural porque estava relacionada ao tamanho do estômago de cada um. Os ornamentos que envolvem os modos nas refeições são bem cuidados. Observei a atenção com a escolha de jogos americanos de bambuzinho, cuias de coco para as sopas e louça simples e rústicas combinadas com os alimentos que iam ser servidos.

Alguns significados se assemelham e aproximam o vegan e o vivo do natural. No estilo de alimentação viva, observamos semelhanças com os outros dois no que diz respeito à vestimenta, que tem uma aparência simples, sem penduricalhos em exagero; o exagero é considerado um tipo "árvore de Natal" de se vestir. As roupas são de algum modo articuladas com a vida no campo: flores nos cabelos e nas estampas das roupas, nas tiaras, nas saias, que não são justas nem curtas, com tecido abundante de algodão e franzidos suaves, assim como nas blusas. Em determinada ocasião, tive o prazer de levar um vegano e seu filho do Recreio dos Bandeirantes ao centro do Rio. Estavam de bermuda, camiseta de malha e sandálias havaianas, o que era costume na vida deles; e assim foram ao centro. Levavam um saco (estopa) com batata yacon, produzida no sítio de um amigo, para outro amigo, proprietário de um restaurante no centro da cidade. Embora as pessoas que passavam na Avenida Antonio Carlos, às três horas da tarde, estranhassem aquele modo de se vestir, para eles estranho seria se tivessem de mudar de roupa para ir a algum lugar.

O padrão de beleza do corpo também se assemelha nos três estilos e não foge à regra que destaca a feminilidade. $\mathrm{O}$ rosto das mulheres é considerado mais bonito quando lavado, sem maquiagem ou com uma suave, quase imperceptível. A beleza considerada e valorizada como natural é aquela que se opõe à da maquiagem feita com batom e sombras fortes ou coloridas 
nos olhos, tida como supérflua e um luxo que encobre a beleza natural. $\mathrm{O}$ tom de pele costuma ser claro e sem marcas. A pele, no rosto das modelos que posavam para folhetos veganos, era imaculada, parecia nunca ter conhecido sequer uma espinha na vida. O tom moreno e bronzeado de sol que o carioca típico almeja ter, ou um tom de pele popularmente conhecido como "marrom bombom", não se constitui como referencial de beleza. Os cabelos nem sempre são pintados, o que confere uma aparente autenticidade, natural, porque identifica a idade sem disfarçar o envelhecimento, também natural no homem.

O estilo natural de beleza feminina se distancia do que se conhece popularmente como "mulher fatal". O corpo deve viver confortável, dentro de roupas folgadas, sem presilhas, cintas ou qualquer tipo de modeladores. Pode estar mais exposto como os de algumas tribos ou em praias de nudismo, mas não em biquínis pequenos, do tipo "fio dental ou asa delta", ou decotes acentuados. O corpo $n u$ é natural, representa um estado do homem na Natureza, e as técnicas modernas de rejuvenescimento e cirurgia deturpam essa ordem natural; são repudiadas, então, por serem uma forma de civilidade artificial. Nesse sentido, os seios nem sempre vivem em sutiãs, o que não representa desleixo, mas certa sensualidade num sentido romântico.

Os modos mais valorizados são os discretos e simples, reproduzindo um padrão de comportamento que privilegia a cordialidade e a elegância. Não se fala alto nos restaurantes; a postura, os gestos ou as expressóes faciais dos sujeitos demonstram um controle das emoções. A predisposição é a de um comportamento não expansivo nem invasivo, reafirmando uma sensação de civilidade, que seria natural na convivência social como um valor humano, contrário à barbárie. A civilidade segue códigos sociais de boas maneiras, envolvendo um controle das emoções já iniciado há muito, desde o final da Idade Média, e que se intensificou na Renascença. A incorporação de um padrão de comportamento 
social com forte controle de emoções e compulsão de policiamento foi se dando inconscientemente nas relaçôes sociais, sem que percebêssemos esse processo lento de mudança:

A modelagem por esses meios objetiva tornar automático o comportamento socialmente desejável, uma questão de autocontrole, fazendo com que o mesmo pareça à mente do indivíduo resultar de seu livre-arbítrio e ser de interesse de sua própria saúde ou dignidade humana (Elias, 1994, p. 153).

Segundo Elias, o mecanismo de controle de emoções orienta as relaçôes sociais com a censura de modos e é produto de uma época que atribui um caráter de anormalidade aos que não conseguem atingir determinado nível de controle de suas emoções: "O modo como são compreendidos [os doentes, anormais e criminosos] varia de acordo com os modelos historicamente mutáveis da formação de afetos" (p. 146). O homem convive com restrições sociais de diversas formas, estabelecendo tensões e equilíbrios de suas emoções e satisfações. Nesse sentido, os modos naturistas também se desejam civilizados. Expressam um equilíbrio de emoções e uma satisfação na socialização da alimentação, com maneiras acolhedoras, como modos que se contrapóem à competitividade selvagem e agressiva dos "bárbaros", considerados assim por outra civilidade negativa.

A ingestão de carne está associada a essa civilidade negativa, uma ideia de agressão e depredação da Natureza, associada a um ímpeto imperialista destrutivo. A fartura de comida não é exatamente um desejo no naturismo; o ideal é poder comer o necessário, somente o necessário. Os banquetes não são comuns nesse estilo. Há certa virtude em se comer a quantidade certa; o desperdício de alimentos é filho do descontrole, herdeiro da aristocracia e da desigualdade social. O sentido que se quer dar ao comer está associado a uma sociabilidade na justeza da necessidade que a Natureza impõe. É muito comum a prática de aproveitamento 
integral de alimentos nas técnicas culinárias naturistas, veganas e vivas, privilegiando seu uso integral, com cascas, o que reforça a disposição para a sustentabilidade.

Todos esses estilos buscam a sustentabilidade do planeta, a continuidade de ações capazes de proteger a biodiversidade e os ecossistemas, num desenvolvimento economicamente sustentável - de modo que se minimize a utilização de recursos naturais e resíduos tóxicos e se sigam diretrizes ecológicas de respeito à natureza para a construção de um futuro melhor para a humanidade, com garantia de saúde ao nosso planeta, afinal, a única moradia objetivamente possível hoje. Ao planeta, é atribuído um significado sacro de deusa, "senhora de si", com um sentido bricolado no romantismo dos séculos XVIII e XIX. Os elementos míticos de Gaia circulam nesses estilos, mas no natural estão mais presentes. 